\title{
Diagnosis of Malignant Biliary Stricture: More is Better
}

\author{
Hyun Jik Lee and Kwang Bum Cho \\ Department of Internal Medicine, Keimyung University School of Medicine, Daegu, Korea
}

See "Usefulness of Endoscopic Transpapillary Tissue Sampling for Malignant Biliary Strictures and Predictive Factors of Diagnostic Accuracy" by Hiroki Tanaka, Shimpei Matsusaki, Youichirou Baba, et al., on page 174-180.

Biliary strictures have various etiologies. ${ }^{1}$ Their accurate diagnosis is still a challenge, often requiring a multidisciplinary approach. The most important differentiation is between the benign and malignant etiology. However, there is no consensus regarding an adequate diagnostic approach to malignant biliary strictures (MBS). Moreover, various etiologies of MBS may complicate the choice of diagnostic tools.

In this issue of Clinical Endoscopy, Tanaka et al. report the results of a retrospective analysis of endoscopic transpapillary tissue sampling for MBS and factors predictive of diagnostic accuracy. ${ }^{2}$ The authors showed that a combination of forceps biopsy, brush cytology, aspiration cytology, and endoscopic nasobiliary drainage cytology improved the diagnostic accuracy of MBS, ${ }^{2}$ findings which are similar to those of a previous study. ${ }^{3}$

Major malignancies leading to MBS include pancreatic adenocarcinoma and cholangiocarcinoma. Surgical literature series show that $15 \%-24 \%$ of patients undergoing resection for suspected MBS based on preoperative imaging or endoscopic evaluation have a benign etiology. ${ }^{4-8}$ Thus, accurate preoperative tissue diagnosis is necessary to increase the likelihood of complete resection and to avoid perioperative morbidity and mor-

Received: January 30, 2018 Revised: March 9, 2018

Accepted: March 10, 2018

Correspondence: Kwang Bum Cho

Division of Gastroenterology and Hepatology, Department of Internal Medicine, Keimyung University School of Medicine, 56 Dalseong-ro, Jung-gu, Daegu 41931, Korea

Tel: +82-53-250-8096, Fax: +82-53-250-7434, E-mail: chokb@dsmc.or.kr ORCID: https://orcid.org/0000-0003-2203-102X

(cc) This is an Open Access article distributed under the terms of the Creative Commons Attribution Non-Commercial License (http://creativecommons.org/ licenses/by-nc/3.0) which permits unrestricted non-commercial use, distribution, and reproduction in any medium, provided the original work is properly cited. tality. Despite multiple diagnostic methods being available, no single test has sufficient sensitivity to differentiate between benign biliary strictures and MBS. Noninvasive laboratory and radiological tests including transabdominal ultrasound, computed tomography (CT) and magnetic resonance cholangiopancreatography (MRCP) are the common initial modalities used for suspected MBS. Transabdominal ultrasound is usually the initial imaging test, but has limited ability for detection of MBS. ${ }^{9}$ CT can provide staging information on local spread, nodal and vascular involvement, and metastasis, and has much higher sensitivity for detection of MBS. ${ }^{10}$ However, CT still only has a sensitivity of $40 \%-77 \% .^{11-13}$ With a sensitivity of $96 \%-99 \%$ and specificity of $85 \%$ for differentiation of malignant and benign causes of obstruction, ${ }^{14} \mathrm{MRCP}$ has become the preferred imaging modality in evaluation of MBS.

Endoscopic retrograde cholangiopancreatography (ERCP) is the most widely used diagnostic and therapeutic modality in MBS. ERCP is useful in identifying the location and extent of MBS and acquiring specimens through brush cytology and intraductal biopsy. Endoscopic brush cytology has a sensitivity of $23 \%-56 \%$ and specificity of $95 \%$ in the diagnosis of MBS. ${ }^{15-18}$ Various factors can influence the poor yield of brush cytology and include both tumor characteristics and procedure-related factors. ${ }^{19}$ Navaneethan et al. reviewed nine studies that included 730 patients to compare the effectiveness of endoscopic brush cytology and intraductal biopsy in the diagnosis of MBS. $^{3}$ The pooled sensitivity and specificity of brushings and intraductal biopsies was $45 \%$ and $99 \%$, and $48.1 \%$ and $99.2 \%$, respectively. The sensitivity and specificity can be increased to $59.4 \%$ and $100 \%$, respectively, by combining the two methods. They showed that brushings and biopsies alone have limited 
sensitivity for the diagnosis of MBS, but that sensitivity can be increased by combining the methods. ${ }^{3}$ Factors contributing to diagnostic yield include tumor characteristics (location, size, and type of stricture), cytology preparation and interpretation, and ERCP technique (skill and experience of the endoscopist). ${ }^{20}$ However, these factors are not fully understood.

Tanaka et al. demonstrated that a combination of diagnostic methods based on the suspected etiology of MBS using imaging studies can improve diagnostic accuracy. ${ }^{2}$ Importantly, the sensitivity of forceps biopsy for biliary lesions (extrahepatic cholangiocarcinoma, 91.4\%) was significantly higher than that for extrabiliary lesions (pancreatic cancer, intrahepatic cholangiocarcinoma, gallbladder cancer, metastatic cancer, and postoperative recurrence, $66.3 \%$ ). This study has several limitations including a retrospective design, small number of pathologic diagnoses confirmed with surgical specimens, and relatively low sensitivity of tissue sampling for extrabiliary lesions. However, the authors showed that sensitivities differ according to tumor characteristics such as presence or absence of direct invasion of the bile duct. These real-world results emphasize the importance of choosing an accurate and appropriate diagnostic method based on the characteristics of strictures using imaging and endoscopic findings. Further prospective and larger scale studies are needed to determine the diagnostic yield and comparative effectiveness of ERCP-based sampling methods and endoscopic ultrasound-guided fine needle aspiration (EUSFNA) according to tumor characteristics.

Several studies performed to improve the sensitivity of brush cytology showed that multiple brushings can help to increase the diagnosis rate but that brush length or stricture dilation failed to improve diagnostic yield. ${ }^{19,21}$ Moving the sheath and brush across the stricture at least 15 times and sending the sheath rinse along with the brush is a simple modification in technique that can improve the yield of brush cytology for biliary strictures. ${ }^{22}$ Triple-tissue sampling including endoluminal FNA, brush cytology, and forceps biopsy or additional endoluminal FNA can increase the sensitivity to $77 \%{ }^{18}$ In addition, fluorescence in situ hybridization (FISH) and flow cytometry can improve the diagnostic yield of ERCP. ${ }^{23}$ Probe-based confocal laser endomicroscopy (pCLE) for real-time in vivo histological imaging has the potential to be a valuable diagnostic tool for difficult cases. ${ }^{24}$ However, FISH and pCLE are not widely used and require further validation for routine clinical practice. Single-operator cholangioscopy for direct visualization of the biliary tract was recently developed, and can provide additional direct images and biopsy sampling to improve the diagnosis of MBS, but still has several limitations. ${ }^{25}$

To conclude, standard ERCP, conventional sampling methods, and EUS-FNA alone are insufficient to differentiate MBS from benign strictures, and combining different modalities is necessary to increase the diagnostic sensitivity. Emerging technology such as FISH, pCLE, and cholangioscopy can provide better sensitivity and may improve diagnostic yield. Tissue sampling sensitivity and specificity varies according to the etiology of cancer and characteristics of the stricture. Therefore, the diagnostic approach for MBS needs to be individualized and requires consideration of multiple factors including the cause of malignancy and the endoscopist's preferred technique.

\section{Conflicts of Interest}

The authors have no financial conflicts of interest.

\section{REFERENCES}

1. Bowlus CL, Olson KA, Gershwin ME. Evaluation of indeterminate biliary strictures. Nat Rev Gastroenterol Hepatol 2016;13:28-37.

2. Tanaka H, Matsusaki S, Baba Y, et al. Usefulness of endoscopic transpapillary tissue sampling for malignant biliary strictures and predictive factors of diagnostic accuracy. Clin Endosc 2018;51:174-180.

3. Navaneethan U, Njei B, Lourdusamy V, Konjeti R, Vargo JJ, Parsi MA. Comparative effectiveness of biliary brush cytology and intraductal biopsy for detection of malignant biliary strictures: a systematic review and meta-analysis. Gastrointest Endosc 2015;81:168-176.

4. Gerhards MF, Vos P, van Gulik TM, Rauws EA, Bosma A, Gouma DJ. Incidence of benign lesions in patients resected for suspicious hilar obstruction. Br J Surg 2001;88:48-51.

5. Clayton RA, Clarke DL, Currie EJ, Madhavan KK, Parks RW, Garden OJ. Incidence of benign pathology in patients undergoing hepatic resection for suspected malignancy. Surgeon 2003;1:32-38.

6. Hayat JO, Loew CJ, Asrress KN, McIntyre AS, Gorard DA. Contrasting liver function test patterns in obstructive jaundice due to biliary strictures [corrected] and stones. QJM 2005;98:35-40.

7. Corvera CU, Blumgart LH, Darvishian F, et al. Clinical and pathologic features of proximal biliary strictures masquerading as hilar cholangiocarcinoma. J Am Coll Surg 2005;201:862-869.

8. Wakai T, Shirai Y, Sakata J, et al. Clinicopathological features of benign biliary strictures masquerading as biliary malignancy. Am Surg 2012;78:1388-1391.

9. Bowlus CL, Olson KA, Gershwin ME. Evaluation of indeterminate biliary strictures. Nat Rev Gastroenterol Hepatol 2017;14:749.

10. Nesbit GM, Johnson CD, James EM, MacCarty RL, Nagorney DM, Bender CE. Cholangiocarcinoma: diagnosis and evaluation of resectability by $\mathrm{CT}$ and sonography as procedures complementary to cholangiography. AJR Am J Roentgenol 1988;151:933-938.

11. Tillich M, Mischinger HJ, Preisegger KH, Rabl H, Szolar DH. Multiphasic helical CT in diagnosis and staging of hilar cholangiocarcinoma. AJR Am J Roentgenol 1998;171:651-658.

12. Rösch T, Meining A, Frühmorgen S, et al. A prospective comparison of the diagnostic accuracy of ERCP, MRCP, CT, and EUS in biliary strictures. Gastrointest Endosc 2002;55:870-876.

13. Heinzow HS, Kammerer S, Rammes C, Wessling J, Domagk D, Meister T. Comparative analysis of ERCP, IDUS, EUS and CT in predicting malignant bile duct strictures. World J Gastroenterol 2014;20:10495-10503.

14. Romagnuolo J, Bardou M, Rahme E, Joseph L, Reinhold C, Barkun AN. Magnetic resonance cholangiopancreatography: a meta-analysis of test performance in suspected biliary disease. Ann Intern Med 2003;139:547557.

15. Burnett AS, Calvert TJ, Chokshi RJ. Sensitivity of endoscopic retrograde cholangiopancreatography standard cytology: 10-y review of the literature. J Surg Res 2013;184:304-311.

16. Ponchon T, Gagnon P, Berger F, et al. Value of endobiliary brush cytolo- 
gy and biopsies for the diagnosis of malignant bile duct stenosis: results of a prospective study. Gastrointest Endosc 1995;42:565-572.

17. Glasbrenner B, Ardan M, Boeck W, Preclik G, Möller P, Adler G. Prospective evaluation of brush cytology of biliary strictures during endoscopic retrograde cholangiopancreatography. Endoscopy 1999;31:712-717.

18. Jailwala J, Fogel EL, Sherman S, et al. Triple-tissue sampling at ERCP in malignant biliary obstruction. Gastrointest Endosc 2000;51(4 Pt 1):383390.

19. de Bellis M, Fogel EL, Sherman S, et al. Influence of stricture dilation and repeat brushing on the cancer detection rate of brush cytology in the evaluation of malignant biliary obstruction. Gastrointest Endosc 2003;58:176182.

20. Singh A, Gelrud A, Agarwal B. Biliary strictures: diagnostic considerations and approach. Gastroenterol Rep (Oxf) 2015;3:22-31.

21. Fogel EL, deBellis M, McHenry L, et al. Effectiveness of a new long cytology brush in the evaluation of malignant biliary obstruction: a prospec- tive study. Gastrointest Endosc 2006;63:71-77.

22. Amog-Jones GF, Chandra S, Jensen C, Johlin FC. Including the sheath rinse to improve cellular yield in biliary brushing cytology. Clin Endosc 2017;50:614-616.

23. Levy MJ, Baron TH, Clayton AC, et al. Prospective evaluation of advanced molecular markers and imaging techniques in patients with indeterminate bile duct strictures. Am J Gastroenterol 2008;103:12631273.

24. Meining A, Frimberger E, Becker V, et al. Detection of cholangiocarcinoma in vivo using miniprobe-based confocal fluorescence microscopy. Clin Gastroenterol Hepatol 2008;6:1057-1060.

25. Navaneethan U, Hasan MK, Lourdusamy V, Njei B, Varadarajulu S, Hawes RH. Single-operator cholangioscopy and targeted biopsies in the diagnosis of indeterminate biliary strictures: a systematic review. Gastrointest Endosc 2015;82:608-614.e2. 